\title{
Treatment Patterns of Newly Diagnosed Rheumatoid Arthritis Patients from a Commercially Insured Population
}

\author{
David M. Kern • Lawrence Chang - Kalyani Sonawane • \\ Cynthia J. Larmore - Natalie N. Boytsov - Ralph A. Quimbo • \\ Joseph Singer · John T. Hinton · Sze-jung Wu • Andre B. Araujo
}

Received: February 27, 2018 / Published online: May 30, 2018

(C) The Author(s) 2018

\section{ABSTRACT}

Introduction: To describe treatment patterns in newly diagnosed rheumatoid arthritis (RA) patients in a large, nationally representative managed-care database.

Methods: Newly diagnosed RA patients were identified from 07/01/2006-08/31/2014. Patients had $\geq 1$ RA diagnosis by a rheumatologist, or $\geq 2$ non-rheumatologist RA diagnoses $\geq 30$ days apart, or RA diagnosis followed by a disease-modifying antirheumatic drug (DMARD) prescription fill within 1 year. Patients were $\geq 18$ years old at index (earliest date fulfilling diagnostic criteria) and had $\geq 6$ and 12 months of pre- and post-index health plan enrollment, respectively. Patterns of

Enhanced digital features To view enhanced digital features for this article go to https://doi.org/10.6084/ m9.figshare.6205478.

D. M. Kern · K. Sonawane - R. A. Quimbo · J. Singer . S. $\mathrm{Wu}$

HealthCore, Inc, Wilmington, DE, USA

L. Chang · C. J. Larmore - N. N. Boytsov ·

A. B. Araujo ( $\square)$

Eli Lilly and Company, Indianapolis, IN, USA

e-mail: araujo_andre@lilly.com

J. T. Hinton

Anthem, Inc, Indianapolis, IN, USA
DMARD treatment, including conventional synthetic DMARDs (csDMARD), tumor necrosis factor inhibitors (TNFi), non-TNFi, and Janus kinase inhibitors (JAKi), were captured during follow-up.

Results: Of the 63,101 RA patients identified, $73 \%$ were female; mean age was 57 years. During an average of $3.5 \pm 2.1$ years of follow-up, $45 \%$ of patients never received a DMARD, $52 \%$ received a csDMARD $(94 \pm 298$ mean \pm SD days from index), $16 \%$ a TNFi (315 \pm 448 days), $4 \%$ a non-TNFi (757 \pm 660 days), and $<1 \%$ a JAKi. Among DMARD recipients, the most common treatment patterns were: receiving csDMARDs only (68\%), adding a TNFi as second-line therapy after initiation of a csDMARD (12\%), and receiving only a TNFi (6\%) during follow-up. Among those not on DMARDs, the all-cause usage of an opioid was $56 \%$ and $19 \%$ had chronic opioid use ( $\geq 180$ days supplied).

Conclusions: Despite American College of Rheumatology recommendations for DMARD treatment of RA, nearly half of newly diagnosed RA patients received no DMARD therapy during follow-up. These data identify a treatment gap in RA management.

Funding: Eli Lilly \& Company.

Keywords: Arthritis; Antirheumatic agents; Guideline adherence; Medication adherence; Practice patterns; Physicians' rheumatoid 


\section{INTRODUCTION}

Rheumatoid arthritis (RA) affects an estimated 1.3 million adults in the United States (US), is twice as prevalent in women as in men, and is associated with a range of signs and symptoms that include pain, fatigue, and joint stiffness [1-3]. Because of its debilitating symptoms, RA strains the resources of healthcare systems, exacts severe economic burdens on patients and their families, and diminishes quality of life along with patients' ability to work and function normally [4, 5]. Inflammation caused by the disease can lead to cartilage damage and destruction of the joints [6]. RA patients may have multiple comorbidities and psychosocial impairments including cardiovascular disease, osteoporosis, interstitial lung disease, infections, malignancies, fatigue, depression, and cognitive dysfunction, among others [7]. Thus, it is vital that RA disease activity is controlled to lessen the disease-related burden on patients' personal lives and the healthcare system as a whole.

The American College of Rheumatology (ACR) RA treatment recommendations specify the use of conventional, synthetic diseasemodifying antirheumatic drugs (csDMARDs) as first-line therapy for newly diagnosed RA patients to minimize or prevent progressive damage to joints and improve long-term outcomes $[8,9]$. Currently, methotrexate, hydroxychloroquine, sulfasalazine, or other csDMARDs are well established as first-line DMARD treatments for RA; however, multiple therapeutic options are now available beyond csDMARDs for patients who fail to achieve their treatment goal on these agents $[6,8,10]$, including biologic therapies and a Janus kinase inhibitor (JAKi) [11-13].

Despite the increasing availability of therapeutic options for RA management, not all patients receive recommended therapy. Physician-perceived barriers to therapy include cost to patient and insurance/formulary coverage [14]. Patient factors that may influence therapy choice include the fear of side effects and a belief in adequate disease control despite many patients exhibiting discordant moderate or higher RA disease activity scores [15].
Attainment of remission or low disease activity remains challenging for many patients [16]. The management of RA has implications on the overall cost and quality of care for patients, providers, and payers [6, 10, 17-19].

The availability of recent population-based estimates of RA treatment patterns is limited. Such information would be of interest to parties involved in the management of this disease. This study aimed to address this knowledge gap by examining treatment patterns within a population of newly diagnosed RA patients using a large, nationally representative managed-care database.

\section{METHODS}

\section{Study Design and Data Source}

This observational cohort study queried medical and prescription claims from the HealthCore Integrated Research Database (HIRD) ${ }^{\mathrm{SM}}$, a repository of longitudinal claims data for approximately 40 million health plan enrollees across the US. The study population of interest was newly diagnosed RA patients. The study cohort consisted of patients identified during the period from July 1, 2006 through August 31, 2014 based on a combination of claims-based algorithm [20, 21]. The index date was defined as the earliest date on which a patient fulfilled one of the three algorithm criteria. Study data were handled in compliance with all applicable Health Insurance Portability and Accountability Act (HIPAA) rules. Patient anonymity and confidentiality were preserved with data de-identification throughout. Investigational Review Board (IRB) informed consent requirements were waived for this non-experimental study, which was conducted under the research exception provisions of the Privacy Rule, 45 CFR 164.514(e).

\section{Inclusion/Exclusion Criteria}

Study patients were $\geq 18$ years on their index date and had continuous enrollment with both medical and pharmacy benefits during the 
6-month period preceding the index date and for $\geq 1$ year post-index. To be considered newly diagnosed patients, no RA diagnoses were allowed during the 6-month pre-index period. Patients meeting any one of three claims-based criteria were included: (1) presence of $\geq 1$ medical claim for an RA diagnosis (ICD-9 714.0x, 714.1x, or $714.2 \mathrm{x}$ ) by a rheumatologist; (2) $\geq 2$ medical claims with an RA diagnosis by a non-rheumatologist occurring at least 30 days apart; or, (3) presence of $\geq 1$ medical claim with an RA diagnosis occurring concurrently with or followed by a medical or pharmacy claim for any DMARD therapy within 1 year. Patients were followed beyond 1 year until they reached the end of the study period, left the health plan, or died, whichever occurred first. Patients with $\geq 1$ claim of a cancer diagnosis (ICD-9 code 140.xx-209.3x, 230.xx-234.xx) during the 6-month pre-index period were excluded from the study.

\section{Treatment Pattern Definitions}

Patterns of DMARD treatment-including csDMARDs, biologic tumor necrosis factor inhibitors (TNFi; etanercept, adalimumab, infliximab, certolizumab, and golimumab), biologic non-TNFi (abatacept, rituximab, tocilizumab, anakinra), and JAKi (tofacitinib)-were assessed during follow-up. Additionally, use of prescription pain medications (opioids, nonsteroidal anti-inflammatory drugs [NSAIDs], muscle relaxants, and anticonvulsants) and steroids (oral and injectable glucocorticoids) were examined. All-cause chronic opioid use was defined as receiving $\geq 180$ days supply of opioid medication during the follow-up period. Discontinuation of DMARD treatment was considered as the absence of a claim for a DMARD within 90 days after the last day supplied of the most recent medication claim. The discontinuation date was defined as the last medication claim date plus the days supplied for that claim. Switching was defined as the filling of a DMARD class that was different from any medication in the current regimen or most recent prior medication while not continuing the original therapy; stopping and restarting the same medication was not considered a switch.
Add-on therapy included the filling of a second DMARD class while maintaining continuous therapy with a previously prescribed DMARD. A maximum of three treatment changes (adding on or switching therapy) were captured for each patient, resulting in the capture of up to four lines of DMARD treatment. Medication dosage was not captured in this study.

Two sensitivity analyses were conducted: (1) limiting the analysis to patients identified during January 1, 2010 through August 31, 2014 to account for the potential evolution in therapeutic management and treatment recommendations in recent years, and (2) requiring patients to have three distinct RA diagnosis on distinct dates when the diagnostic workups or tests (e.g., imaging of joint, laboratory test for C-reactive protein, synovial fluid analysis rheumatoid factor, cyclic citrullinated peptide, erythrocyte sedimentation rate) used for diagnosing/ruling out RA were not included, AND visited a rheumatologist at time of first diagnosis.

\section{Baseline Characteristics}

Prespecified comorbid conditions were defined as the presence of $\geq 1$ diagnosis code for the condition of interest during the 6-month preindex period. The Quan-Charlson Comorbidity Index (QCI) was calculated to quantify the burden of comorbid disease in this population [22]. The specialty of the physician associated with the RA diagnosis was identified on the index date medical claim. If physician information was not available on the index date, the claim closest to the index date (either pre- or post-index) with a diagnosis for RA was used to determine diagnosing specialty.

\section{Statistical Analysis}

This single-cohort study of RA patients was descriptive in nature, and treatment patterns were analyzed within the entire cohort with no comparison group. Descriptive statistics (means, standard deviations, medians, frequencies, and percentages) were reported for each outcome of interest. All analyses were conducted using SAS Enterprise Guide v7.1 (Cary, NC, USA). 


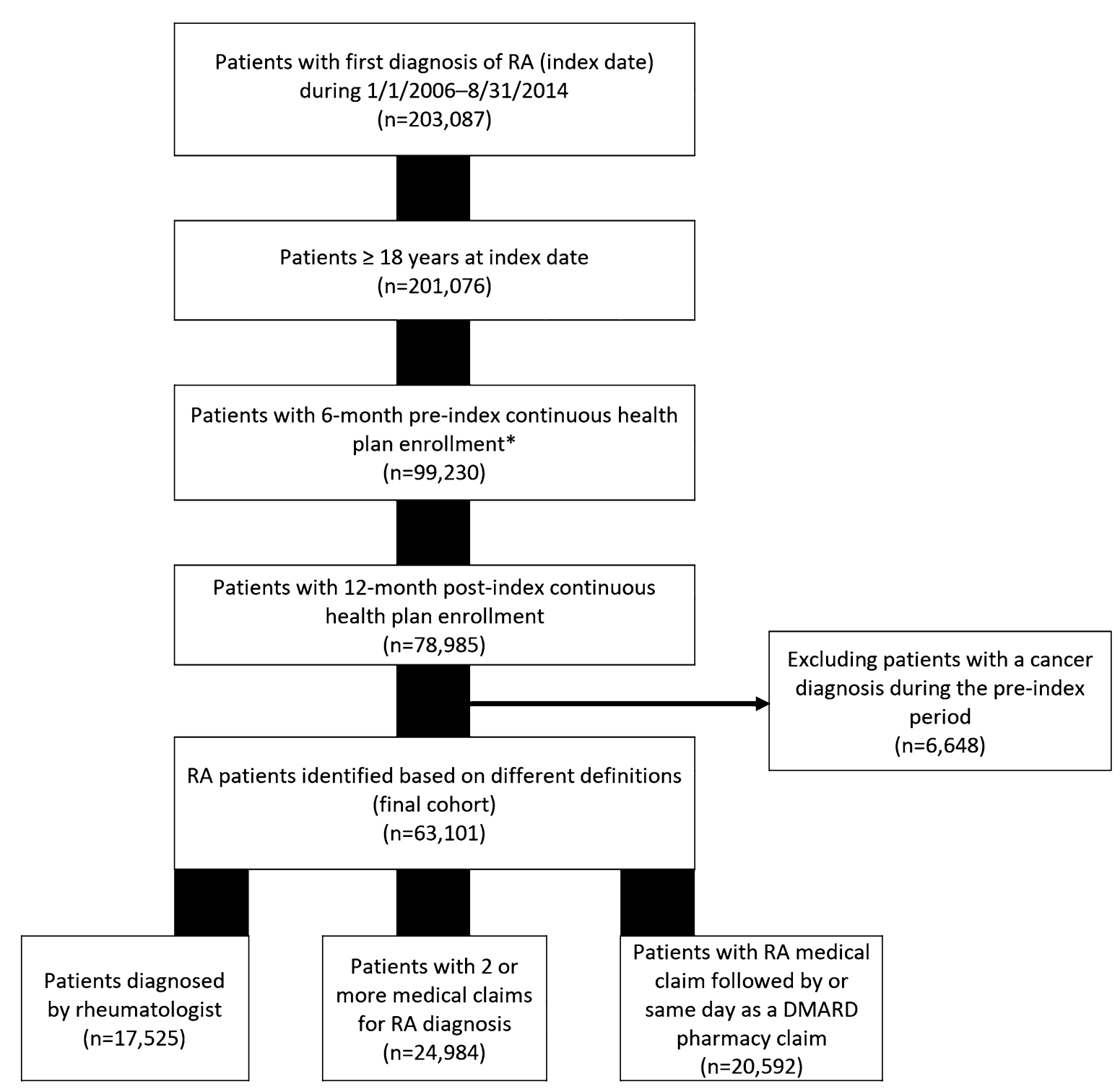

*By requiring 6 months pre-index criteria the identification period of patients effectively becomes $7 / 1 / 2006$ through $8 / 31 / 2014$

Fig. 1 Patient selection for the study and the number of patients included in the final analytic cohort. ${ }^{*}$ By requiring 6 months pre-index criteria the identification period of patients effectively becomes 7/1/2006 through 8/31/2014

\section{RESULTS}

\section{Demographics and Baseline Data}

After applying inclusion and exclusion criteria (Fig. 1), there were 63,101 RA patients with mean \pm SD age of $57 \pm 15.6$ years, and $72.7 \%$ were female (Table 1). Most patients were enrolled in preferred provider organization (PPO) health plans (72.5\%), and $27.8 \%$ had Medicare Advantage or Medicare Supplemental plus Part D coverage. Nearly half of the study population $(44.2 \%)$ was diagnosed or treated by a rheumatologist at index. Hypertension (40.5\%), dyslipidemia (34.0\%), and 
Table 1 Baseline patient characteristics $(N=63,101)$

\begin{tabular}{|c|c|}
\hline Characteristic & $\begin{array}{l}\text { Mean } \pm \text { SD or } \\
n(\%)\end{array}$ \\
\hline Female & $45,854(72.7)$ \\
\hline Age at index (years) & $57.0 \pm 15.6$ \\
\hline \multicolumn{2}{|l|}{ Geographic region } \\
\hline Northeast & $12,181(19.3)$ \\
\hline Midwest & $18,111(28.7)$ \\
\hline South & $16,580(26.3)$ \\
\hline West & $13,467(21.3)$ \\
\hline Unknown & $2,762(4.4)$ \\
\hline \multicolumn{2}{|l|}{ Health plan type } \\
\hline $\mathrm{HMO}$ & $14,002(22.2)$ \\
\hline $\mathrm{PPO}$ & $45,775(72.5)$ \\
\hline CDHP & $3324(5.3)$ \\
\hline $\begin{array}{l}\text { Medicare Advantage, Supplemental } \\
\text { and Part D }\end{array}$ & $17,543(27.8)$ \\
\hline \multicolumn{2}{|c|}{ Treating/prescribing physician specialty } \\
\hline Rheumatologist & $27,922(44.2)$ \\
\hline Internal medicine & $7171(11.4)$ \\
\hline Family medicine/general practice & $6429(10.2)$ \\
\hline Unknown & $2687(4.3)$ \\
\hline All others & $18,892(29.9)$ \\
\hline QCI & $0.9 \pm 1.3$ \\
\hline \multicolumn{2}{|l|}{ QCI categories } \\
\hline 0 & $29,870(47.3)$ \\
\hline $1-2$ & $26,829(42.5)$ \\
\hline$>3$ & $6402(10.1)$ \\
\hline \multicolumn{2}{|l|}{ Comorbid conditions $^{a}$} \\
\hline Hypertension & $25,525(40.5)$ \\
\hline Dyslipidemia & $21,464(34.0)$ \\
\hline Osteoarthritis & $19,642(31.1)$ \\
\hline Mental illness & $12,903(20.4)$ \\
\hline Type 2 diabetes & $9075(14.4)$ \\
\hline Unspecific arthritis & $8919(14.1)$ \\
\hline
\end{tabular}

Table 1 continued

\begin{tabular}{ll}
\hline Characteristic & $\begin{array}{l}\text { Mean } \pm \text { SD or } \\
n(\%)\end{array}$ \\
\hline Respiratory conditions & $8790(13.9)$ \\
Fibromyalgia & $8768(13.9)$ \\
Hypothyroidism & $8493(13.5)$ \\
Inflammatory polyarthritis & $6385(10.1)$ \\
\hline
\end{tabular}

$S D$ standard deviation, $H M O$ health maintenance organization, $P P O$ preferred provider organization, $C D H P$ consumer driven health plan, $Q C I$ Quan-Charlson index

${ }^{a}$ Comorbid conditions counted if a single occurrence of the code appeared, listed are conditions that affected at least $10 \%$ of the RA population. Comorbid autoimmune conditions included lupus erythematous (9.8\%), dermatitis (6.2\%), psoriatic arthritis (4.1\%), psoriasis (3.2\%), ankylosing spondylitis (1.4\%), Crohn's disease (1.3\%), and ulcerative colitis $(1.1 \%)$

osteoarthritis (31.1\%) were among the most commonly observed comorbid conditions.

\section{Treatment Patterns}

\section{Follow-up and Time to Treatments}

Patients were followed for a mean of $3.5 \pm 2.1$ years after their index date, and 50\% of patients were followed for at least 3 years (Table 2). The mean time from index date to first use of each DMARD treatment class was $94 \pm 298$ days for csDMARD $(n=32,518)$, $315 \pm 448$ days for biologic TNFi $(n=10,360)$, $757 \pm 660$ days for non-TNFi $(n=2,228)$, and $1,254 \pm 800$ days for JAKi users $(n=274)$. For patients who received a prescription pain medication, the mean time to treatment with pain medication was $194 \pm 346$ days.

\section{DMARD Medication Use}

Treatments were examined by DMARD class through 90 days from index date and through the entire post-index period (Fig. 2). Many patients $(53.8 \%)$ received no DMARD therapy within 90 days after the index date; $44.9 \%$ of patients never received DMARD therapy during the entire follow-up period. However, examining rates by medical specialty, $78.9 \%$ of patients 
Table 2 Follow-up time and time to treatment among patients newly diagnosed with rheumatoid arthritis $(n=63,101)$

\begin{tabular}{ll}
\hline & $\begin{array}{l}\text { Mean } \pm \text { SD/n } \\
(\%)\end{array}$ \\
\hline $\begin{array}{l}\text { Total follow-up time from index to end of } \\
\text { follow-up (years) }\end{array}$ & $3.5 \pm 2.1$ \\
$\geq 2$ years of follow-up & $44,795(71.0)$ \\
$\geq 3$ years of follow-up & $31,293(49.6)$ \\
$\geq 4$ years of follow-up & $21,699(34.4)$ \\
$\geq 5$ years of follow-up & $14,657(23.2)$ \\
Treatment characteristics & \\
Time to treatment (days from index date & \\
to first fill) & \\
csDMARD ( $n=32,518)$ & $94 \pm 298$ \\
Biologic TNFi $(n=10,360)$ & $315 \pm 448$ \\
Biologic non-TNFi $(n=2228)$ & $757 \pm 660$ \\
JAKi $(n=274)$ & $1254 \pm 800$ \\
Time to pain medication (days) & $194 \pm 346$ \\
(n $=49,123)$ & \\
Opioids $(n=41,148)$ & $302 \pm 431$ \\
NSAIDs (n=32,935) & \\
COX 2 inhibitors $(n=17,292)$ & $403 \pm 2.1$ \\
Acetaminophen $(n=16)$ & $789 \pm 984$ \\
Muscle relaxants $(n=315)$ & $449 \pm 495$ \\
Anticonvulsants $(n=12,243)$ & $517 \pm 619$ \\
csDMARD use & \\
From & \\
Number & \\
use & \\
Number & \\
\hline
\end{tabular}

Table 2 continued

\begin{tabular}{ll}
\hline & $\begin{array}{l}\text { Mean } \pm \text { SD } / \mathbf{n} \\
(\%)\end{array}$ \\
\hline $\begin{array}{l}\text { Number of patients with biologic } \\
\text { use diagnosed by rheumatologist }\end{array}$ & $7395(65.7)$ \\
$\begin{array}{l}\text { Total follow-up time (years) } \\
\text { From index to first use(days) }\end{array}$ & $3.9 \pm 2.2$ \\
$\begin{array}{l}\text { From first use to end of follow-up } \\
\text { (days) }\end{array}$ & $328 \pm 462$ \\
$\begin{array}{l}\text { From csDMARD (in those receiving } \\
\text { csDMARD) (days) }\end{array}$ & $388 \pm 446$ \\
\hline
\end{tabular}

treated by a rheumatologist received DMARD therapy at some point during follow-up, compared with just $36.3 \%$ of those seen by a nonrheumatologist. Within 90 days of index date, csDMARD therapy was the most prevalent $(41.5 \%)$, followed by a biologic TNFi (4.5\%), and a non-TNFi $(<1 \%)$ or JAKi $(<1 \%)$. When examining the entire follow-up period, there was a slight increase in csDMARD use (51.5\%), with larger increases observed for biologic TNFi (16.4\%) and biologic non-TNFi (3.5\%) therapies. JAKi use remained rare, occurring in $<1 \%$ of the population.

\section{Detailed Treatment Patterns}

Detailed treatment patterns in the newly diagnosed RA population are depicted in Fig. 3 . Among patients who received DMARD treatment $(n=34,795), \quad 67.5 \%$ received only csDMARD during follow-up. Initiating a csDMARD and adding a TNFi as second-line therapy was the most common route to receiving biologic therapy (12.4\% of treated patients), while treatment with a TNFi without ever receiving a csDMARD was the next most common $(5.5 \%)$. While uncommon $(1.2 \%$ of all DMARD-treated patients), non-TNFi use was most likely to occur after starting on a csDMARD, adding a TNFi, and then switching to a non-TNFi while remaining on a csDMARD.

Of patients who did not receive DMARD therapy $(n=28,306)$ during follow-up, many received symptomatic treatment; $56.5 \%$ 


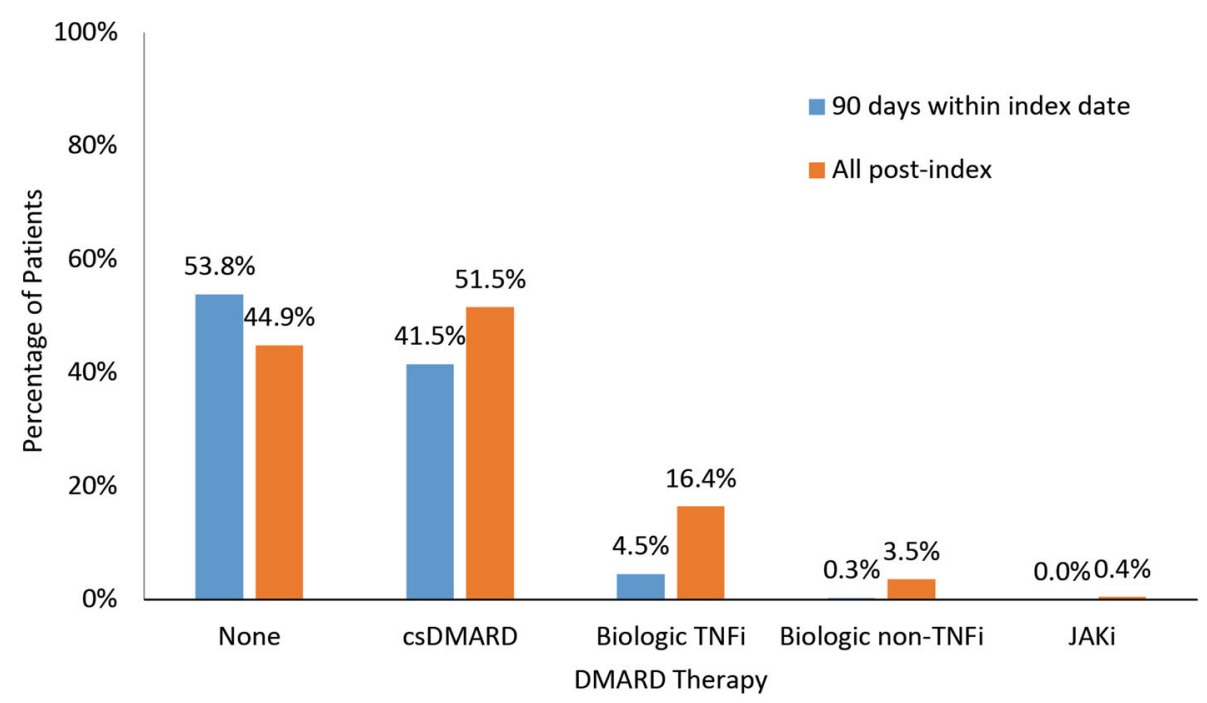

Fig. 2 DMARD medication use by class within 90 days of the index date (blue bars) and at any time during the post-index period (orange bars) $(n=63,101)$

received opioids, $19.4 \%$ had evidence of chronic opioid use, and more than a third (37.9\%) received steroids. In contrast, among those who received DMARD therapy $(n=34,795), 72.3 \%$ received opioids, $24.8 \%$ were chronic opioid users, and $72.9 \%$ received steroids at any time during follow-up.

Table 3 describes treatment line characteristics based on first DMARD treatment. The two most common first treatment changes were moving from a csDMARD to TNFi therapy either by adding on the TNFi therapy to the csDMARD regimen or switching from csDMARD therapy to TNFi monotherapy. Of 31,217 patients who started csDMARD as first-line therapy, $42.6 \%$ had no change, $32.8 \%$ discontinued, and $24.5 \%$ $(n=7656)$ either added on or switched to a new DMARD class. Among these 7,656 csDMARDinitiating patients who had second-line therapy, $62.2 \%$ had no additional therapy change, $14.5 \%$ discontinued, and $23.3 \%$ added or switched to the new therapy (i.e., moved to a third treatment line).

In patients who started a TNFi as first-line therapy $(n=3,303), 41.6 \%$ had no change in therapy class, $18.1 \%$ discontinued, and $40.3 \%$ either added or switched DMARD class. In 1,332 TNFi first-line users who had second-line therapy, $65.5 \%$ remained on their second-line therapy, $18.5 \%$ switched or added-on therapy, and $15.9 \%$ discontinued. As for the group of patients who initiated a non-TNFi as first-line therapy ( $n=339$ ), $33.0 \%$ had no change, $27.7 \%$ discontinued, and $39.2 \%$ patients either added or switched to a new therapy. In non-TNFi firstline users moving to a second-line therapy ( $n=133), 35.3 \%$ added on or switch therapy.

Occurrence of a second treatment change was relatively infrequent, as $62.2 \%$ of those on second-line therapy had no additional changes observed. The most common treatment change was discontinuation of therapy $(15.0 \%$ of all second-line patients); thus just $22.8 \%$ of second-line patients moved on to a third line ( $n=2,078,6.0 \%$ of all treated patients). Threequarters of third-line therapies contained a csDMARD, while TNFi (32.7\%) and non-TNFi $(47.4 \%)$ therapies were also observed. JAKi use rose above $1 \%$, occurring in $5.7 \%$ of third-line treatment regimens.

\section{DISCUSSION}

This study provides insight into treatment patterns among newly diagnosed RA patients in a large managed-care setting and highlights important potential gaps in treatment. Treatment rates in our study population indicate that a large proportion of patients (nearly half of this 

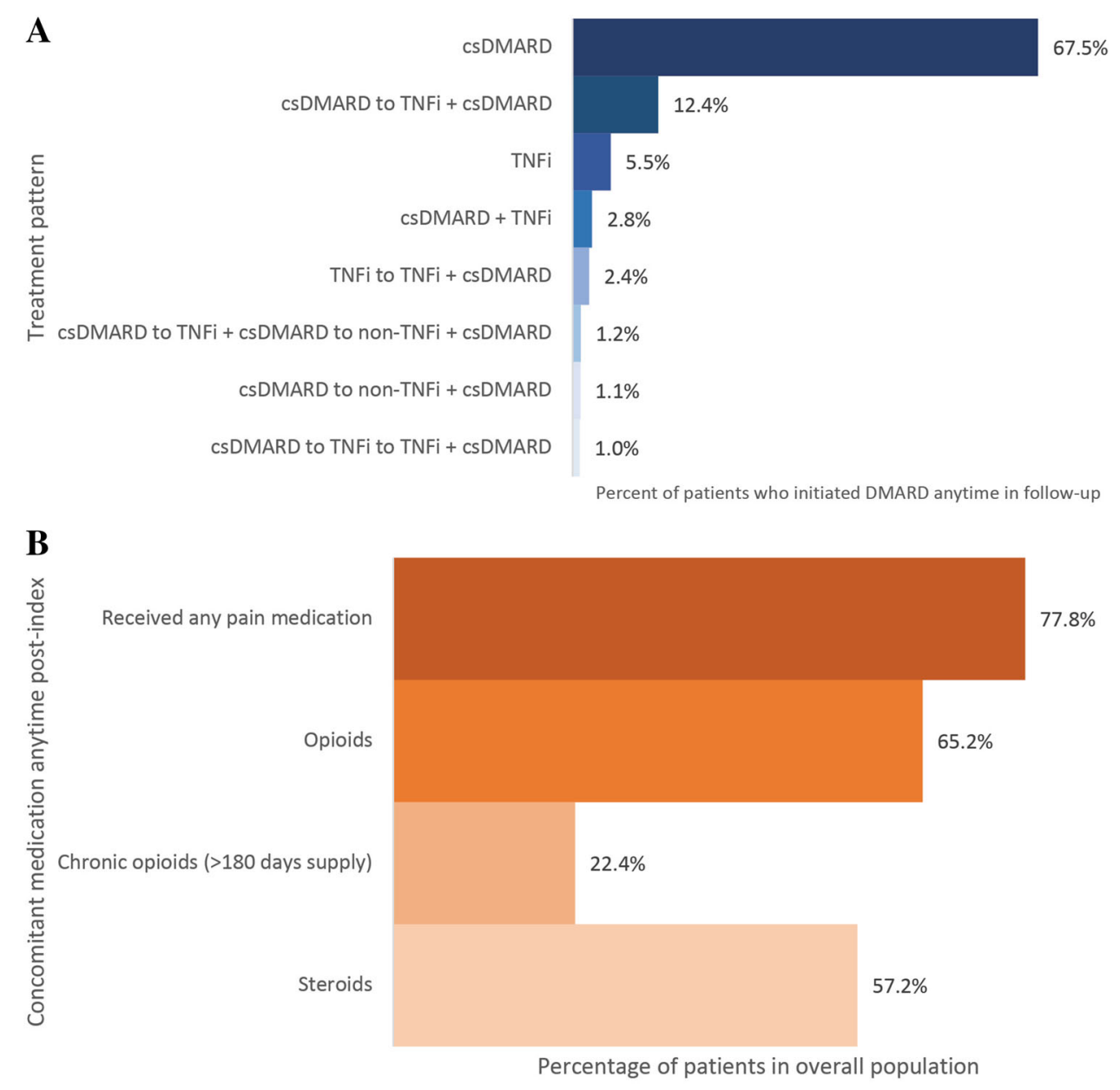

Fig. 3 Treatment patterns in patients with rheumatoid arthritis. a Treatment patterns within rheumatoid arthritis patients who received DMARD therapy $(n=34,795)$. Medications linked by a ' + ' symbol indicates the medication classes were received simultaneously. $\mathbf{b}$ Non-DMARD treatments in RA patients $(n=63,101)$

cohort of patients with RA) did not receive guideline-recommended DMARD treatment. In the course of the study, only slightly more than one-half of the cohort received a csDMARD, less than one-fifth were treated with a biologic TNFi, and very few were treated with a biologic nonTNFi or a JAKi.

Among patients who received DMARD therapy, the use of csDMARD mono-class therapy was the most commonly initiated first-line treatment. Although the use of biologics was not prevalent during the first-line treatment, the proportion of biologics increased among patients who had second, third, and fourth lines of treatment. The use of JAKi increased during follow-up among patients who had more than one treatment line, but the proportion remained quite low. However, this DMARD class was introduced into the market as a treatment option late in this study observation period.

Prior published studies have reported patterns of DMARD drug utilization for RA treatment similar to what was observed in our study-csDMARDs were the most commonly used treatment, and while fewer patients initiated treatment with biologics as expected $[23,24]$, their use increased over time; [24] furthermore, while our study showed a surprisingly low rate of DMARD use, other studies have reported comparable rates of DMARD treatment [1, 25-27]. 
Table 3 Treatment line characteristics based on first DMARD treatment in patients newly diagnosed with rheumatoid arthritis and treated with a DMARD therapy $(n=34,795)$

\begin{tabular}{|c|c|c|c|c|}
\hline & & First DMARD rec & $\mathrm{ed}^{\mathrm{a}}$ & \\
\hline & $\begin{array}{l}\text { Overall } \\
(n=34,795) \\
\text { Mean } \pm S D / n(\%)\end{array}$ & $\begin{array}{l}\text { csDMARD } \\
(n=31,217) \\
\operatorname{Mean} \pm \operatorname{SD} / n(\%)\end{array}$ & $\begin{array}{l}\text { TNFi } \\
(n=3,303) \\
\text { Mean } \pm \text { SD } / n(\%)\end{array}$ & $\begin{array}{l}\text { non-TNFi } \\
(n=339) \\
\text { Mean } \pm \text { SD } / n(\%)\end{array}$ \\
\hline First line characteristics & $34,795(100.0)$ & $31,217(100.0)$ & $3303(100.0)$ & $339(100.0)$ \\
\hline Treatment line contains ${ }^{\mathrm{b}}$ & & & & \\
\hline csDMARD & $31,217(89.7)$ & $31,217(100.0)$ & $56(1.7)$ & $12(3.5)$ \\
\hline TNFi & $3303(9.5)$ & $56(0.2)$ & $3303(100.0)$ & $0(0.0)$ \\
\hline non-TNFi & $339(1.0)$ & $12(0.0)$ & $0(0.0)$ & $339(100.0)$ \\
\hline JAKi & $4(<0.1)$ & $0(0.0)$ & $0(0.0)$ & $0(0.0)$ \\
\hline $\begin{array}{l}\text { Length of first-line therapy } \\
\text { (days) }\end{array}$ & $724 \pm 693$ & $730 \pm 694$ & $700 \pm 694$ & $466 \pm 528$ \\
\hline First treatment change character & & & & \\
\hline No change & $14,750(42.4)$ & $13,313(42.6)$ & $1373(41.6)$ & $112(33.0)$ \\
\hline Switch therapy & $2587(7.4)$ & $2096(6.7)$ & $399(12.1)$ & $91(26.8)$ \\
\hline Add medication(s) & $6529(18.8)$ & $5560(17.8)$ & $933(28.2)$ & $42(12.4)$ \\
\hline Discontinue treatment & $10,929(31.4)$ & $10,248(32.8)$ & $598(18.1)$ & $94(27.7)$ \\
\hline Second line characteristics & $9116(100.0)$ & $7656(100.0)$ & $1332(100.0)$ & $133(100.0)$ \\
\hline Treatment line contains ${ }^{\mathrm{b}}$ & & & & \\
\hline csDMARD & $6888(75.6)$ & $5612(73.3)$ & $1197(89.9)$ & $84(63.2)$ \\
\hline TNFi & $7888(86.5)$ & $6901(90.1)$ & $936(70.3)$ & $52(39.1)$ \\
\hline non-TNFi & $885(9.7)$ & $704(9.2)$ & $143(10.7)$ & $44(33.1)$ \\
\hline JAKi & $61(0.7)$ & $56(0.7)$ & $4(0.3)$ & $1(0.8)$ \\
\hline $\begin{array}{l}\text { Length of second-line therapy } \\
\text { (days) }\end{array}$ & $748 \pm 680$ & $746 \pm 672$ & $795 \pm 729$ & $447 \pm 582$ \\
\hline Second treatment change charac & istics & & & \\
\hline No change & $5673(62.2)$ & $4764(62.2)$ & $873(65.5)$ & $41(30.8)$ \\
\hline Switch therapy & $877(9.6)$ & $700(9.1)$ & $141(10.6)$ & $36(27.1)$ \\
\hline Add medication(s) & $1201(13.2)$ & $1084(14.2)$ & $106(8.0)$ & $11(8.3)$ \\
\hline Discontinue treatment & $1365(15.0)$ & $1108(14.5)$ & $212(15.9)$ & $45(33.8)$ \\
\hline Third line characteristics & $2078(100.0)$ & $1784(100.0)$ & $247(100.0)$ & $47(100.0)$ \\
\hline Treatment line contains ${ }^{\mathrm{b}}$ & & & & \\
\hline csDMARD & $1552(74.7)$ & $1416(79.4)$ & $121(49.0)$ & $15(31.9)$ \\
\hline TNFi & $679(32.7)$ & $524(29.4)$ & $138(55.9)$ & $17(36.2)$ \\
\hline
\end{tabular}


Table 3 continued

\begin{tabular}{|c|c|c|c|c|}
\hline & \multirow[b]{2}{*}{$\begin{array}{l}\text { Overall } \\
(n=34,795) \\
\text { Mean } \pm S D / n(\%)\end{array}$} & \multicolumn{3}{|c|}{${\text { First DMARD } \text { received }^{a}}^{a}$} \\
\hline & & $\begin{array}{l}\text { csDMARD } \\
(n=31,217) \\
\text { Mean } \pm S D / n(\%)\end{array}$ & $\begin{array}{l}\text { TNFi } \\
(n=3,303) \\
\text { Mean } \pm \text { SD } / n(\%)\end{array}$ & $\begin{array}{l}\text { non-TNFi } \\
(n=339) \\
\text { Mean } \pm \text { SD } / n(\%)\end{array}$ \\
\hline non-TNFi & $984(47.4)$ & $860(48.2)$ & $100(40.5)$ & $25(53.2)$ \\
\hline JAKi & $119(5.7)$ & $109(6.1)$ & $7(2.8)$ & $3(6.4)$ \\
\hline $\begin{array}{l}\text { Length of third-line therapy } \\
\text { (days) }\end{array}$ & $537 \pm 546$ & $528 \pm 539$ & $606 \pm 598$ & $535 \pm 486$ \\
\hline
\end{tabular}

Third treatment change characteristics

\begin{tabular}{|c|c|c|c|c|}
\hline No change & $1237(59.5)$ & $1072(60.1)$ & $137(55.5)$ & $28(59.6)$ \\
\hline Switch therapy & $303(14.6)$ & $251(14.1)$ & $38(15.4)$ & $14(29.8)$ \\
\hline Add medication(s) & $278(13.4)$ & $229(12.8)$ & $47(19.0)$ & $2(4.3)$ \\
\hline Discontinue treatment & $260(12.5)$ & $232(13.0)$ & $25(10.1)$ & $3(6.4)$ \\
\hline Fourth line characteristics & $581(100.0)$ & $480(100.0)$ & $85(100.0)$ & $16(100.0)$ \\
\hline \multicolumn{5}{|l|}{ Treatment line contains ${ }^{b}$} \\
\hline csDMARD & $359(61.8)$ & $285(59.4)$ & $65(76.5)$ & $9(56.3)$ \\
\hline TNFi & $242(41.7)$ & $199(41.5)$ & $38(44.7)$ & $5(31.3)$ \\
\hline non-TNFi & $218(37.5)$ & $184(38.3)$ & $30(35.3)$ & $4(25.0)$ \\
\hline $\mathrm{JAKi}$ & $61(10.5)$ & $56(11.7)$ & $4(4.7)$ & $1(6.3)$ \\
\hline Length of fourth-line therapy & $447 \pm 474$ & $425 \pm 454$ & $567 \pm 541$ & $460 \pm 602$ \\
\hline
\end{tabular}

(days)

Fourth treatment change characteristics

\begin{tabular}{lllll} 
No change & $319(54.9)$ & $262(54.6)$ & $50(58.8)$ & $7(43.8)$ \\
Switch therapy & $116(20.0)$ & $96(20.0)$ & $14(16.5)$ & $6(37.5)$ \\
Add medication(s) & $278(47.8)$ & $229(47.7)$ & $47(55.3)$ & $2(12.5)$ \\
Discontinue treatment & $60(10.3)$ & $49(10.2)$ & $10(11.8)$ & $1(6.3)$ \\
\hline
\end{tabular}

a Data stratified by first line JAKi use not shown due to insufficient sample size for analysis $(n=4)$

b "Treatment line contains": among patients receiving a first-, second-, third-, or fourth-line of therapy, the following tabulates the numbers of each DMARD received during the line of therapy. Multiple treatments may be present during any given treatment line

Our results showed that RA patients diagnosed by rheumatologists had higher rates of DMARDs prescribed (79\%) compared with only slightly more than a third of the patients diagnosed by non-rheumatologists. The higher rate of DMARD use among those treated by a rheumatologist is consistent with data from the ACR's RISE (Rheumatology Informatics System for Effectiveness) registry of rheumatology practices, which showed that $91 \%$ of RA patients were on a DMARD at their last clinical encounter [28]. This could help to explain some 
of the inconsistencies observed in the DMARD treatment patterns in this study relative to treatment recommendations, as less than half of the RA patients were diagnosed by a rheumatologist.

This difference in DMARD treatment rates by medical specialty may be driven by three factors: first, rheumatologists are likely more familiar and up to date with RA treatment recommendations and thus more likely to prescribe appropriate therapy; second, claimsbased diagnoses coming from a rheumatologist for RA may be more accurate than those coming from non-rheumatologists in which rule-out diagnoses may be more common; and third, non-rheumatologists may exhibit less comfort with prescribing or managing RA patients on DMARD therapies. Further commentary on the limitations of using administrative claims to identify RA patients can be found in the 'Strengths and Limitations' section below.

The use of steroids and pain medications, including chronic opioid use, in the DMARD untreated population, while not as high as in the DMARD-treated patients, is problematic. Symptomatic treatment alone, without use of DMARDs, is not effective in preventing further joint damage in RA. Khanna et al. reported similar results in a Medicare population: nearly 68 and $48 \%$ of these RA patients had $\geq 1$ prescription fill for opioid analgesics and steroids, respectively [23]. In the overall study population, more than two-thirds received opioids, with slightly more than one-fifth considered chronic users, and more than a half of all patients received steroids. The use of opioids and steroids was more common in those patients receiving DMARD therapy at any time during follow-up compared with those who never received a DMARD during the study period. Unfortunately, it is a limitation of claims data that reasons for use of medications cannot be explicitly determined. For instance, the presence of opioid use does not necessarily mean they were being used for treatment of RA symptoms, but may have been used for other causes of pain unrelated to their RA, such as low back pain or surgery. The claims data do not specify a diagnosis for which a medication was prescribed, only that it was dispensed.
While symptomatic management alone is inconsistent with treatment recommendations and quality metrics for RA management, it could well be part of a broader trend in which $3-4 \%$ of adult Americans are treated with opioids for pain control [29]. While clinical studies [27] and surveys [30-32] have reported shortterm pain relief associated with opioid use, few studies have investigated longer-term outcomes for opioid analgesics for pain therapy [30]. While pain management is a key aspect to successfully treating RA, current data inform of considerable death and addiction-related risksmore than 165,000 people died from opioid overdosing related to pain management in the US during 1999-2014, [31] an estimated 1.9 million people abused or were dependent on opioid pain medicines during $20[13,33]$ and in 2014, more than 10 million people in the US reported using prescription opioids for nonmedical reasons [34].

Also concerning is the relatively frequent use of steroids in this patient cohort. Even at low doses, steroids such as prednisone are associated with elevations in blood pressure, blood glucose, and lipid levels, as well as increased osteoporosis risk [35]. An assessment of steroid use in a cohort mirroring the US population's proportion of women suggests that care must be exercised to ensure that treatments do not exacerbate conditions like osteoporosis and attendant bone fracture risks $[1,5]$.

These results may help to inform decisionmaking by stakeholders engaged in the management of RA. Future treatment patterns may respond to an increased awareness of the treatment recommendations and the introduction of new therapies and therapeutic indications on formulary decisions and payment structures.

DMARDs are recommended for all newly diagnosed patients according to ACR treatment recommendations $[9,36,37]$. In addition, DMARD use among patients diagnosed with RA is one of the quality metrics established by the National Quality Forum [38], the Center for Medicare and Medicaid (CMS) Physician Quality Reporting System [39], and the National Committee for Quality Assurance Healthcare Effectiveness Data and Information Set [40], which require reporting of the percentage of 
adults with RA treated with DMARD therapy-a metric which also factors into CMS Star ratings [41]. The results observed in this study raise an important concern of a potential care quality gap in RA management.

\section{Strengths and Limitations}

The use of a large, geographically diverse, administrative claims database provided this study with several key strengths. First, the data allowed us to retrospectively observe the longitudinal treatment patterns in newly diagnosed RA patients over a period of 1-9 years (mean, 3.5 years) after their initial RA diagnosis. Second, a sensitivity analysis limiting the observation period to 2010 onward showed consistent results, and thus the findings are a reflection of historical treatment patterns over the past decade as well as recent treatment practices. Finally, these data provide real-world evidence of disease management rather than being limited to the strict guidelines of a clinical trial or other controlled experiment. This study includes a contemporary patient population and presents a view of the current treatment landscape.

While there were clear strengths of this study, these findings must be viewed against some important limitations. First, we identified patients newly initiating RA medication after a 6-month period in which there were no claims for RA medications or RA diagnoses before the index RA medication claim/RA diagnosis code. This approach may not have captured the true incident RA population, i.e., prevalent RA cases may be included, and as a result, our results may be conservatively biased. Second, the minimum continuous enrollment required was 12 months; however, patients were followed beyond the 12-month timeframe until the end of the study period, and their patterns later into enrollment may be affected by loss to follow-up. The mean observation period of 3.5 years from index may offer insufficient time to fully observe the actual use of more advanced DMARD therapies as biologics or JAKi. Finally, our analysis focused on commercially insured patients, possibly under-representing elderly patients enrolled in Medicare.

Furthermore, diagnosis codes are good indicators but not guarantees of the presence of disease as they may be subject to miscoding or may be included as a rule-out criterion. As noted, the reliance on administrative claims (a combination of ICD-9 codes from medical claims and claims for DMARD therapy), without access to medical records, is potentially limiting in identifying RA patients. Studies examining the validity of administrative claims to identify RA patients have found mixed results depending on the algorithm used. Typically the use of multiple claims with RA diagnoses improved the positive predictive value of the definitions, and requiring a diagnosis from a rheumatologist improves the algorithm even further [42-44]. Studies that utilized a more focused code list of RA diagnoses, such as the one used in this study, tended to have higher validity compared with those that used all ICD-9 codes starting with 714 [44]. While our definition of RA may include some patients who do not truly have RA, the algorithm was developed with the goal of minimizing this occurrence. We also conducted a sensitivity analysis using a much more restrictive (i.e., specific) definition of RA, and study results were not fundamentally different.

In general, claims databases are subject to common limitations including the inability to account for medications from other sources such as over-the-counter purchases or samples from providers. Claims data provide limited insight into the clinical status of patients, particularly their severity or activity of their disease and the process surrounding moving onto DMARD therapy-for example, whether DMARD was offered then declined; prescribed and never filled; filled and not used; or not offered at all. Similarly, it is unknown whether patients not seen by a rheumatologist were referred but declined, or not referred. Reasons for initiation of one DMARD class over another, such as the selection of a non-TNFi or a JAKi as the index DMARD therapy, are unknown, and these patients may differ from the general RA population. 


\section{CONCLUSIONS}

Nearly half (45\%) of the RA patients in our study did not receive DMARD therapy at any time during the follow-up period, while the use of pain medications and steroids was high. The most common DMARD treatment pattern was receiving only csDMARD monotherapy with a much smaller portion receiving biologic therapy at any time. Less than half of patients were diagnosed with RA by a rheumatologist and is the most likely reason for the variance in adherence to treatment recommendations. Future research efforts may build upon this work to understand why this treatment gap exists, to develop solutions to address this unmet need, and to ultimately understand how treatment patterns in RA patients are associated with disease activity, quality of life, and clinical and economic outcomes.

\section{ACKNOWLEDGEMENTS}

Funding. The study and article processing charges was funded by Eli Lilly \& Company. All authors had full access to all of the data in this study and take complete responsibility for the integrity of the data and accuracy of the data analysis.

Medical Writing and/or Editorial Assistance. Bernard Tulsi and Mukul Singhal, employees of HealthCore, Inc., provided writing support for this manuscript. Anthony J. Zagar, an employee of Eli Lilly and Company, provided statistical support for the study design.

Authorship. All named authors meet the International Committee of Medical Journal Editors (ICMJE) criteria for authorship for this article, take responsibility for the integrity of the work as a whole, and have given their approval for this version to be published.

Disclosures. David M Kern is a former employee of HealthCore, Inc. Kalyani Sonawane is a former employee of HealthCore, Inc. Lawrence Chang is a former employee of Eli
Lilly and Company. Cynthia J Larmore is a former employee and stock owner of Eli Lilly and Company. Natalie $\mathrm{N}$ Boytsov is a employee/stock owner of Eli Lilly and Company. Andre B Araujo is an employee/stock owner of Eli Lilly and Company. Ralph A Quimbo is an employee of HealthCore, Inc. Joseph Singer is an employee of HealthCore, Inc. Sze-jung $\mathrm{Wu}$ is an employee of HealthCore, Inc. John T Hinton is an employee of Anthem, Inc.

Compliance with Ethics Guidelines. Study data were handled in compliance with all applicable Health Insurance Portability and Accountability Act (HIPAA) rules. Patient anonymity and confidentiality were preserved with data de-identification throughout. Investigational Review Board (IRB) informed consent requirements were waived for this non-experimental study, which was conducted under the research exception provisions of the Privacy Rule, 45 CFR 164.514(e).

Open Access. This article is distributed under the terms of the Creative Commons Attribution-NonCommercial 4.0 International License (http://creativecommons.org/licenses/ by-nc/4.0/), which permits any noncommercial use, distribution, and reproduction in any medium, provided you give appropriate credit to the original author(s) and the source, provide a link to the Creative Commons license, and indicate if changes were made.

\section{REFERENCES}

1. Crane MM, Juneja M, Allen J, et al. Epidemiology and treatment of new-onset and established rheumatoid arthritis in an insured US population. Arthritis Care Res (Hoboken). 2015;67:1646-55.

2. Helmick CG, Felson DT, Lawrence RC, et al. Estimates of the prevalence of arthritis and other rheumatic conditions in the United States. Part I. Arthritis Rheum. 2008;58:15-25.

3. Salaffi F, Carotti M, Gasparini S, Intorcia M, Grassi $\mathrm{W}$. The health-related quality of life in rheumatoid arthritis, ankylosing spondylitis, and psoriatic arthritis: a comparison with a selected sample of 
healthy people. Health Qual Life Outcomes. 2009; 7:25.

4. Barrett EM, Scott DG, Wiles NJ, Symmons DP. The impact of rheumatoid arthritis on employment status in the early years of disease: a UK community-based study. Rheumatology (Oxford). 2000;39:1403-9.

5. Greenapple R. Trends in biologic therapies for rheumatoid arthritis: results from a survey of payers and providers. Am Health Drug Benefits. 2012;5:83-92.

6. Agarwal SK. Core management principles in rheumatoid arthritis to help guide managed care professionals. J Manag Care Pharm. 2011;17:S03-8.

7. Cutolo M, Kitas GD, van Riel PL. Burden of disease in treated rheumatoid arthritis patients: going beyond the joint. Semin Arthritis Rheum. 2014;43:479-88.

8. Singh JA. American College of Rheumatology guideline for the treatment of rheumatoid arthritis 2015. Arthritis Care Res. 2015;68:1-25.

9. Singh JA, Saag KG, Bridges SL Jr, et al. 2015 American College of Rheumatology Guideline for the Treatment of Rheumatoid Arthritis. Arthritis Rheumatol. 2016;68:1-26.

10. Agarwal SK. Biologic agents in rheumatoid arthritis: an update for managed care professionals. J Manag Care Pharm. 2011;17:S14-8.

11. Genovese MC, Kremer J, Zamani O, et al. Baricitinib in patients with refractory rheumatoid arthritis. N Engl J Med. 2016;374:1243-52.

12. O'Shea JJ, Laurence A, McInnes IB. Back to the future: oral targeted therapy for RA and other autoimmune diseases. Nat Rev Rheumatol. 2013;9:173-82.

13. Yamaoka K. Janus kinase inhibitors for rheumatoid arthritis. Curr Opin Chem Biol. 2016;32:29-33.

14. Kamal KM, Madhavan SS, Hornsby JA, Miller LA, Kavookjian J, Scott V. Use of tumor necrosis factor inhibitors in rheumatoid arthritis: a national survey of practicing United States rheumatologists. Joint Bone Spine 2006;73.

15. Wolfe F, Michaud K. Resistance of rheumatoid arthritis patients to changing therapy: discordance between disease activity and patients' treatment choices. Arthritis Rheum. 2007;56:2135-42.

16. Pavelka K, Kavanaugh AF, Rubbert-Roth A, Ferraccioli G. Optimizing outcomes in rheumatoid arthritis patients with inadequate responses to disease-modifying anti-rheumatic drugs. Rheumatology (Oxford). 2012;51(Suppl 5):v12-21.

17. Birnbaum H, Pike C, Kaufman R, Marynchenko M, Kidolezi Y, Cifaldi M. Societal cost of rheumatoid arthritis patients in the US. Curr Med Res Opin. 2010;26:77-90.

18. Ward MM, Javitz HS, Yelin EH. The direct cost of rheumatoid arthritis. Value Health. 2000;3:243-52.

19. Ward MM, Lubeck D, Leigh JP. Long-term health outcomes of patients with rheumatoid arthritis treated in managed care and fee-for-service practice settings. J Rheumatol. 1998;25:641-9.

20. Hanly JG, Thompson K, Skedgel C. The use of administrative health care databases to identify patients with rheumatoid arthritis. Open Access Rheumatol Res Rev. 2015;7:69-75.

21. Kim SY, Servi A, Polinski JM, et al. Validation of rheumatoid arthritis diagnoses in health care utilization data. Arthritis Res Ther. 2011;13:R32.

22. Quan H, Li B, Couris CM, et al. Updating and validating the Charlson comorbidity index and score for risk adjustment in hospital discharge abstracts using data from 6 countries. Am J Epidemiol. 2011;173:676-82.

23. Khanna R, Smith MJ. Utilization and costs of medical services and prescription medications for rheumatoid arthritis among recipients covered by a state Medicaid program: a retrospective, cross-sectional, descriptive, database analysis. Clin Ther. 2007;29:2456-67.

24. Zhang HF, Gauthier G, Hiscock R, Curtis JR. Treatment patterns in psoriatic arthritis patients newly initiated on oral nonbiologic or biologic diseasemodifying antirheumatic drugs. Arthritis Res Ther. 2014;16:420.

25. Bonafede MM, Fox KM, Johnson BH, Watson C, Gandra SR. Factors associated with the initiation of disease-modifying antirheumatic drugs in newly diagnosed rheumatoid arthritis: a retrospective claims database study. Clin Ther. 2012;34:457-67.

26. Makol A, Davis JM, Crowson CS, Therneau TM, Gabriel SE, Matteson EL. Time trends in glucocorticoid use in rheumatoid arthritis: results from a population-based inception cohort 1980-1994 vs. 1995-2007. Arthritis Care Res. 2014;66:1482-8.

27. Schmajuk G, Trivedi AN, Solomon DH, et al. Receipt of disease-modifying antirheumatic drugs among patients with rheumatoid arthritis in Medicare managed care plans. JAMA. 2011;305:480-6. 
28. Yazdany J, Bansback N, Clowse $M$, et al. The rheumatology informatics system for effectiveness (RISE): a national informatics-enabled registry for quality improvement. Arthritis Care Res (Hoboken) 2016.

29. Boudreau D, Von Korff M, Rutter CM, et al. Trends in long-term opioid therapy for chronic non-cancer pain. Pharmacoepidemiol Drug Saf. 2009; 18:1166-75.

30. Anastassopoulos KP, Chow W, Tapia CI, Baik R, Moskowitz B, Kim MS. Reported side effects, bother, satisfaction, and adherence in patients taking hydrocodone for non-cancer pain. J Opioid Manag. 2013;9:97-109.

31. Gregorian RS Jr, Gasik A, Kwong WJ, Voeller S, Kavanagh S. Importance of side effects in opioid treatment: a trade-off analysis with patients and physicians. J Pain. 2010;11:1095-108.

32. Thielke SM, Turner JA, Shortreed SM, et al. Do patient-perceived pros and cons of opioids predict sustained higher-dose use? Clin J Pain. 2014;30:93-101.

33. Chou R, Deyo R, Devine B, et al. The effectiveness and risks of long-term opioid treatment of chronic pain [Evidence Report/Technology Assessment No. 218]. Agency for Healthcare Research and Quality. http://www.effectivehealthcare.ahrq.gov/ehc/prod ucts/557/1971/chronic-pain-opioid-treatment-repo rt-141007.pdf. Accessed 19 Sep 2016.

34. Multiple cause of death data. CDC WONDER. Centers for Disease Control and Prevention. http:// wonder.cdc.gov/mcd.html. Accessed 19 Sep 2016.

35. Moghadam-Kia S, Werth VP. Prevention and treatment of systemic glucocorticoid side effects. Int J Dermatol. 2010;49:239-48.

36. Saag KG, Teng GG, Patkar NM, et al. American College of Rheumatology 2008 recommendations for the use of nonbiologic and biologic diseasemodifying antirheumatic drugs in rheumatoid arthritis. Arthritis Rheum. 2008;59:762-84.

37. Singh JA, Furst DE, Bharat A, et al. 2012 update of the 2008 American College of Rheumatology recommendations for the use of disease-modifying antirheumatic drugs and biologic agents in the treatment of rheumatoid arthritis. Arthritis Care Res (Hoboken). 2012;64:625-39.

38. (NQF) MSC. NQF-Endorsed Measures for Musculoskeletal Conditions National Quality Forum; 2015 $1 / 2015$.

39. Services CfMM. 2016 Physician Quality Reporting System (PQRS) Measures Groups Specifications Manual 2015.

40. NCQA. Continuous Improvement and the Expansion of Quality Measurement 2011.

41. Services CfMM. Medicare 2015 Part C \& D Star Rating Technical Notes 2014 09/03/2014.

42. Greenlee R, Drahos J, VanWormer J, Landgren O, Koshiol J. PS2-22: Accuracy of Diagnostic Codes to Identify Rheumatoid Arthritis in Archived Electronic Health System Data: Support for Future Cancer Research Network Studies of Lymphoma Risk Pathways. Clinical Medicine \& Research 2013;11:154.

43. Ng B, Aslam F, Petersen NJ, Yu H-J, Suarez-Almazor ME. Identification of rheumatoid arthritis patients using an administrative database: a Veterans Affairs study. Arthritis Care Res. 2012;64:1490-6.

44. Chung CP, Rohan P, Krishnaswami S, McPheeters ML. A systematic review of validated methods for identifying patients with rheumatoid arthritis using administrative or claims data. Vaccine. 2013;31(Suppl 10):K41-61. 